\title{
Co-Flourishing for Sustainability: Buddhist Temple Education and National Compulsory Education in the Dai Cultural Region of Xishuangbanna, China
}

\author{
Yajun Wu1 ${ }^{1}$ Xia Kang ${ }^{2}$ \\ ${ }^{1}$ College of International Studies, Southwest University, Chongqing, China \\ ${ }^{2}$ The University of Hong Kong, Hong Kong, China \\ Email:wuyajun1225@163.com
}

How to cite this paper: Wu, Y. J., \& Kang, X. (2021). Co-Flourishing for Sustainability: Buddhist Temple Education and $\mathrm{Na}$ tional Compulsory Education in the Dai Cultural Region of Xishuangbanna, China. Chinese Studies, 10, 69-87.

https://doi.org/10.4236/chnstd.2021.102006

Received: March 11, 2021

Accepted: March 23, 2021

Published: March 26, 2021

Copyright ( 2021 by author(s) and Scientific Research Publishing Inc. This work is licensed under the Creative Commons Attribution International License (CC BY 4.0).

http://creativecommons.org/licenses/by/4.0/

\begin{abstract}
Buddhist temple education and national compulsory education coexisting in the Dai cultural region of Xishuangbanna is a specific phenomenon in China's educational context. The balance between these two distinct education forms is conducive to the further development of ethnic minority education in this region, so determining how to balance these two forms of education has attracted researchers' interests. In this study, we analyzed the data collected from interviews with 29 participants based on their views and experiences of these two education forms. The results highlight the collision between these two education forms; the possible reasons for this collision are discussed in this paper. We propose that the co-flourishing of these two forms of education could reasonably promote the sustainable development of ethnic minority education in the Dai cultural region of Xishuangbanna.
\end{abstract}

\section{Keywords}

Buddhist Temple Education, National Compulsory Education, Conflict, Co-Flourishing, Ethnic Minority Education

\section{Introduction}

The conflict between Buddhist temple education (BTE) and the national compulsory education (NCE) is threatening the sustainable development of ethnic minority education in the Dai cultural region of Xishuangbanna, China (Hansen, 1999). Compared with the education in most parts of China, the par- 
ticularity of ethnic minority education in the Dai cultural region of Xishuangbanna lies in the coexistence of the BTE and NCE (Li \& Moore, 2014; Zheng, 2011). With the introduction of NCE by the Chinese government in 1986, the NCE was enforced throughout mainland China, including all the ethnic autonomous regions. Since the 1950s, when China's communist regime set up primary and secondary schools in this area, the coexistence of BTE and national education has continued. Since China began to implement the compulsory education policy in 1986, the conflict between the BTE and the NCE has become increasingly difficult to reconcile. Determining how to balance the relationship between BTE and NCE in this region has become an urgent problem to be solved.

Studies on the relationship between the religion and education mainly used college students as research subjects (Voas, 2014; Yang, 2004). We know little about the relationship between BTE and NCE because Chinese students in a compulsory phase were thought to seldom participate in religious activities (Wang \& Uecker, 2017). However, the religious context of Xishuangbanna is different from that of most parts of China in that almost all Dai people in this region believe in Theravāda Buddhism (Li \& Moore, 2014). Some Chinese scholars have realized the significance of protecting BTE in Xishuangbanna, suggesting that BTE is an indispensable part of Dai people's ethnic identity (Chen, 2011; Chen \& Liu, 2011; Zheng, 2012). However, no research has been conducted to elucidate the relationship between BTE and NCE through synthesizing the stakeholders' views and opinions.

China adopted a new religious strategy that has further intensified the contradiction between the BTE and the NCE; consequently, the sustainable future of the BTE in the Dai cultural region of Xishuangbanna is uncertain. Since the $19^{\text {th }}$ National Congress of the Communist Party of China held in October 2017, China has adopted the "religious sinicization" strategy (Chang, 2018). Religious sinicization means that all the existing religious sects in China should "redirect their flow toward state-sponsored channels of sacrality" (Vermander, 2019: p. 4); inevitably, the Chinese government will restrain religion (Vermander, 2019). In this context, the contradiction between BTE and NCE has increased since the voicings of a total ban on BTE began to appear. For instance, the schools in Xishuangbanna have ruled that no monastic robes are allowed on campus. As such, balancing the relationship between BTE and NCE is urgently required for the sustainable development of ethnic minority education in the Dai cultural region of Xishuangbanna. In this context, we examined the conflicts between these two forms of education as well as the possible reasons that lead to the conflicts by exploring the stakeholders' perspectives because their voices revealed the relationship between BTE and NCE.

\section{Research Background}

\subsection{Buddhist Temple Education}

Buddhist temple education refers to the religious educational activities that are 
conducted in Buddhist temples (Dao, 2006; Li \& Moore, 2014). The Dai people attach considerable importance to the BTE, as the saying goes that "the Buddhist temple is the school, the Buddha is the teacher, the Theravāda Buddhist sutra is the textbook, and the Buddhist monks are the students" (Dao \& Cai, 2014: p. $373)$, so the Dai people traditionally thought that education should be conducted in the Buddhist temples. BTE is very popular in the Dai cultural region of Xishuangbanna, China. Traditionally, Dai boys would be sent to the Buddhist temple to study the Buddhist scriptures, the old Dai language, and the concepts of ethics when they reached the age of seven to nine (Zheng, 2011; Zheng \& Xiong, 2013). There is no rigid or inflexible rule on the BTE study period; it usually lasts for three years but can last from months to decades. The tonsure ceremony marks the graduation from BTE, after which the novices may resume secular life or remain in temples to act as senior monks.

Almost all the Dai people in Xishuangbanna believe in Theravāda Buddhism and they have great affection for the BTE. The classical teachings of Theravāda Buddhism state that men should practice personal cultivation for several years in temples as a monk. Since Theravāda Buddhism was first introduced into Xishuangbanna in the $13^{\text {th }}$ century, it has performed two prominent functions in the social life of Dai people. Firstly, the Buddhist precepts and the religious values are embodied in Dai people's behaviors and their social values. Secondly, Theravāda Buddhism and its teachings are integrated within the Dai culture, so the Dai culture is mainly inherited through BTE. The religious activities and the spread of cultural knowledge and religious beliefs are all realized in Buddhist temples (Davis, 2003). BTE is responsible for disseminating Dai culture, such as religious beliefs, Dai cultural knowledge, Dai language, medical science, astronomy, and literary arts. The BTE is highly recommended by the Dai people for its ability to enlighten the Dai nationality; the ethnic characteristics and ethnic culture cannot be preserved without the BTE.

BTE has long been criticized as the cause of the Dai students' poor academic performance, even though it is of significance to the Dai people. BTE is an inevitable part of the Dai ethnic minority in that the transmission of Dai ethnic cultural inheritance, the cultivation of intellectuals, and the harmonious social relationships are all realized through BTE. However, as argued by Li and Moore, BTE has been considered the cause of the Dai students' poor achievement in the NCE (Li \& Moore, 2014). Conversely, others have argued that socio-cultural factors such as students' cultural identity and ethnicity affect students' participation, and, consequently, their scholastic achievement (Brown, 2002; Lemke, 2001; Presmeg, 1998). As Heberer (2017) indicated, "religion is part of national culture and national identity" (Heberer, 2017: p. 115) and students' religious commitment contributes to improving their academic achievement (Jeynes, 1999, 2003; Zern, 1989). To summarize, BTE is the main occasion for the Dai students to realize their religious identity but its positive role has seldom been considered by China's educational officials. 


\subsection{Interrelationship between BTE and NCE}

The interrelationship between BTE and NCE has differed over time. Before the 1950s, the national education in the Dai cultural region of Xishuangbanna had not been developed and almost all the Dai boys attended the Buddhist temples to receive an education with the purpose of being a literate person (Dao, 2006). Since the 1950s, when the authorities introduced primary and secondary schools in this region, the collision between BTE and the national education began. The conflict between BTE and national education has been further aggravated since China began to implement the policy of compulsory education in 1986 ( $\mathrm{Li} \&$ Moore, 2014). Since then, the tension between BTE and NCE has continued, affecting the sustainable development of ethnic minority education in this region. Table 1 traces the changing relationship between BTE and national education from the historical dimension.

\section{Methodology}

In this qualitative study, both the interviewing approach and a documentary review were used to explore the relationship between BTE and NCE. Precisely, as both people's perspectives and their consistent behaviors are inspired by their cultural background (Brand et al., 2006), open-ended interviews were adopted to investigate the participants' views and attitudes toward BTE and NCE. A documentary review was also conducted to understand the governmental attitudes toward the coexistence of BTE and NCE.

\subsection{Participants}

Twenty-nine local people, including two Buddhas (B); three school principles (SP) from Jinghong teachers training school, Menghan junior high school, and Menglong Junior high school; and eight teachers (T) from these three schools; eight monk students (MS); six Dai parents (DP); and two local cadres (LC) from the Jinghong educational bureau, participated in this study. The names of the informants were anonymized by providing alphanumeric labels for the purpose

Table 1. The historical interrelationship between the Buddhist temple education (BTE) and the national education in Xishuangbanna, China.

\begin{tabular}{cccc}
\hline \multirow{2}{*}{ Era } & Buddhist & \multicolumn{2}{c}{ Balance between BTE and National Education } \\
\cline { 3 - 4 } & Temple Situation & BTE & National Education \\
\hline $1912-1949$ & Extensively existed & Dominant & Started to emerge \\
$1950-1966$ & Remained intact & From dominance to extinction & $\begin{array}{c}\text { From the beginning to } \\
\text { dominant position }\end{array}$ \\
$1966-1976$ & Closed or destroyed & Full suspension & Solo existence \\
$1978-1990$ & Restored and reconstructed & Recovery and prevailing & Enrollment reduced \\
1990 s-present & Increased in number & Scale decreased & Dominant \\
\hline
\end{tabular}

*Each village has a Buddhist temple, whereas towns composed of several villages have higher-standard Buddhist temples. 
of ethical correctness. The first letter of the interviewees was selected and capitalized to represent the certain type of the interviewees. For example, the interviewees include three school principles; SP-1 in the labeling system refers to school principles from Menghan Junior high school. The selection criteria for suitable participants included: they had lived and worked in Xishuangbanna for no less than five years, were of Dai ethnicity, and participated in or were familiar with ethnic minority education in Xishuangbanna. However, five Han participants were included because they were familiar with the contrast between BTE and NCE. In total, 24 participants were Dai people and the remaining 5 participants were Han people. In terms of sex, there were 7 women and 22 men. The participants' detailed demographic characteristics are provided in Table 2.

\subsection{Data Collection}

This study lasted 19 days in Jinghong city and Menghai county, which is the town-level administration of Xishuangbanna, whose economy and culture are relatively undeveloped (Figure 1) in June 2019. Jinghong is the site of Xishuangbanna's prefecture government and Menghai is located in the west of Xishuangbanna. These two sites, with different political, economic, and cultural statuses, represent the developed and underdeveloped parts of Xishuangbanna.

All participants participated in the taped interviews after providing their consent. This was conducted because, as Patton (Patton, 2001) pointed out, open-ended questions allow researchers to "understand the world as seen by the respondents" and "capture the points of view of other people" (p. 21). Therefore, all participants were required to answer open-ended questions to gain their attitudes and experiences about these two forms of education. This research method also provides a relaxing environment and permits the respondents to freely express their perceptions and attitudes. The interview mainly focused on the following questions:

Table 2. Demographic characteristics of the participants.

\begin{tabular}{cccc}
\hline Subgroup & Sex & Ethnicity & Total \\
\hline Buddha & 2 men & 2 Dai & 2 \\
\hline \multirow{2}{*}{ Teachers } & 3 women & 3 Dai & 8 \\
& 3 men & 3 Dai & \\
\hline Monk students & 2 men & 2 Han & 8 \\
\hline Parents & 8 men & 8 Dai & 6 \\
& 3 men & 6 Dai & 3 \\
\hline \multirow{2}{*}{ Principles } & 3 women & 2 Han & 1 Dai \\
& 1 men & 1 Han & 2 \\
\hline Cadres & 1 man & Dai & \\
\hline
\end{tabular}




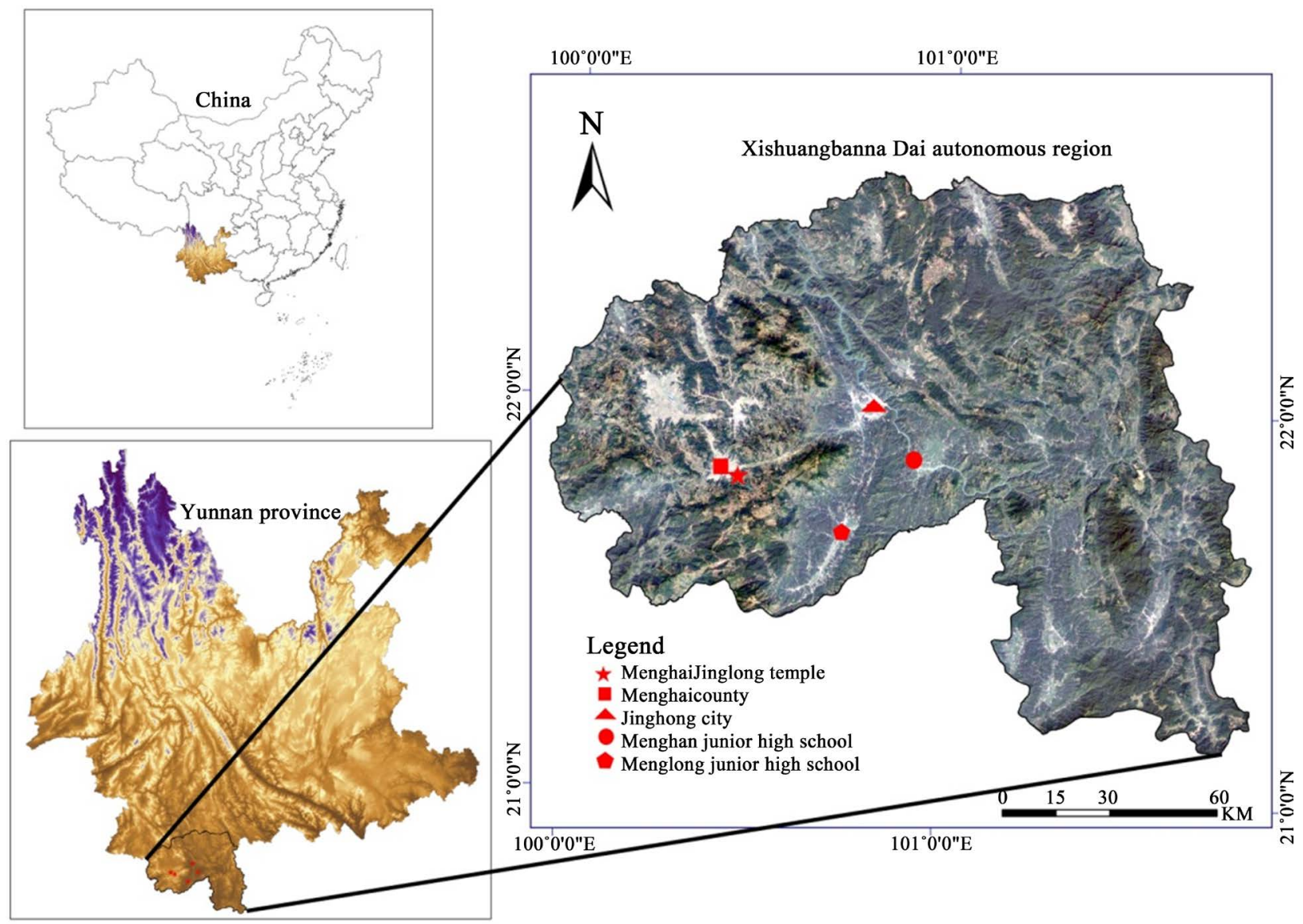

Figure 1. The study areas of this current research.

1) How do you think of the Buddhist temple education in Xishuangbanna?

2) How do you think of the relationship between the BTE and the NCE?

3) What can educators or policymakers do to improve the current state of the ethnic minority education in the Dai cultural region of Xishuangbanna?

4) As parents, why do you send your children to accept the Buddhist temple education?

5) As teachers, what are the challenges you encountered in your education career? And how do you deal with these challenges?

\subsection{Data Analysis}

Data analysis included three steps. First, the taped interviews were transcribed. Secondly, the transcripts and the investigation notes were read repeatedly to gain a comprehensive understanding of the interplay between BTE and NCE that was not constrained by structured methodologies (Patton, 2001). Thirdly, the data were coded and categorized into the headings when emerging themes related to the interplay between these two forms of education were discerned. For example, when asked about the school performance of the monk students, SP-1 told us, "the monk students' school performance is greatly affected by their experiences and their time as monks. Their parents do not expect much of them. Generally, 
they become lazy after they became monks". This reflects the negative influence of BTE on NCE-the conflict between these two forms of education in terms of academic performance.

The transcribed interviews and the investigation notes were coded and counted to present the aspects that account for the conflict between these two forms of education. Notably, some legal documents, including the Constitution of the People's Republic of China, the Education Law of the People's Republic of China, and the Regulations on Ethnic Education of Xishuangbanna Dai Autonomous Prefecture, were read to understand governmental attitudes toward BTE and NCE.

\section{Results}

Through the analysis of legal documents and the interview records, the conflicts between these two concomitant education forms were highlighted. In this section, the four aspects of the conflicts between BTE and NCE are presented. To illustrate each aspect of the conflict between BTE and NCE, the views drawn from legal documents or transcripts were used as evidence.

\subsection{Conflict in the Legal Sphere}

Since 1986, the NCE, also described as "standardized state-controlled education" (Hansen, 1999: p. 160) has been implemented all over China after the guarantee from the Constitution and the Education Law of the People's Republic of China (PRC). Article 18 of the Education Law of the PRC states that "the state implements a nine-year compulsory education system. People's governments of all levels shall take all measures to ensure that school-age children and adolescents attend schools" (National People's Congress of China, 2016: p. 4). Article 19 of the Constitute of the PRC indicates that the Chinese government is committed to universalizing compulsory education (National People's Congress, 2018).

The Chinese citizens have the right to be religious beliefs (Liao, 2019). Both the Constitution of the PRC and the Law of the People's Republic of China on Regional Ethnic Autonomy stipulate that Chinese citizens' freedom of religious belief shall be protected (National People's Congress, 2018) (The NPC Standing Committee, 2001). Buddhist practices refer to the teaching and training process of the identity of teachers and learners to attain nirvana (Macpherson, 2006), which signifies that the development and dissemination of the Buddhist religion cannot be separated from certain educational institutions, even though "religion and education are mutually separated" in mainland China (Nanbu, 2008: p. 227). The Dai ethnic culture in Xishuangbanna is closely intertwined with Theravāda Buddhist doctrine and the Buddhist temple is the main location used for conducting Buddhist practices. Consequently, the BTE is important to the Dai ethnic minority. As such, the Dai people are provided with strong aspirations to attend Buddhist activities and a legal basis for their children to obtain BTE.

In brief, the current Chinese laws foreshadow a conflict between BTE and 
NCE. The Dai people have the legal rights and strong feelings about attending BTE, but the NCE is simultaneously vigorously promoted by different levels of the government in China.

\subsection{Conflict in Students' Academic Performance}

Compared with that of ordinary school students, the monk students' academic achievement is poor, which inevitably reduces parents' trust in BTE. The final examination scores of the monk students show that their scores are unsatisfactory as none of the BTE students are able to pass the examination (Table 3). The monk students' academic achievements fall short of the requirements of educational institutions, which signifies that they may find it difficult to successfully deal with mainstream society, let alone integrate themselves. SP-1 also expressed their worry about this condition: "Their academic performance is poor. In the future, even if they can go to the city to earn a living, they could only engage in the hardest physical labor".

In addition to their poor academic achievement, the monk students' reputation for bad behavior, such as laziness, smoking, drinking, or playing cards, which are strictly prohibited by school education, also aggravates parents' distrust of BTE. Some parents, for example DP-1, complained that "no one cares about my child, and my child learned to be lazy when he was a monk student. What's worse, he even stole money from the temple to buy snacks or play games". Then, the NCE criticizes BTE for its loose management, which resulted in the monk students lacking self-discipline. In relation to this, SP-1 expressed their discontent:

In the first year of junior high school, most of the Dai boys became monks and then they are no longer willing to study. They do not bring the textbooks to the classroom. They do not do homework and seldom read books after being a monk student. Sometimes, they even tore up the new textbooks to fold toys. In a word, the more monk students there are in a classroom, the worse the classroom discipline. Parents' distrust plus criticism from the NCE further intensify the conflict between the NCE and the BTE.

\subsection{Conflict: Enrolment of Students and Schedule}

The collision between BTE and NCE is reflected in the source of students. The Dai tradition holds that only when the boys have served as monks in a Buddhist

Table 3. Monk students' scores for three subjects in the final examination grade 2 in Enman junior high school.

\begin{tabular}{cccccc}
\hline Subject & Number of students & Minimum & Maximum & Mean & SD \\
\hline 1 & 13 & 16 & 45 & 34.00 & 9.967 \\
2 & 13 & 8 & 28 & 18.23 & 5.862 \\
3 & 13 & 11 & 35 & 25.08 & 8.098 \\
\hline
\end{tabular}

Source: Cited in Zheng (2012). 
temple will they become qualified members of Dai society (Davis, 2003). If not, the boys are regarded as ignorant and uncivilized fools and they are not socially recognized and cannot find a wife. Therefore, Dai boys cut their hair and become monks when they reach the ages of seven to nine (Li \& Moore, 2014). However, Article 11 of the Compulsory Education Law of the People's Republic of China states that "any children who has attained to the age of six, their parents or other statutory guardians shall have them enrolled in school to finish compulsory education. For the children in those areas where it is not possible, the initial time of schooling may be postponed to seven years old" (The NPC Standing Committee, 2015). This means that the admission age of NCE in China is the same as the entrance age of BTE and these two forms of education conflict with each other in the enrolment of students.

The frequent religious activities in the Dai cultural region of Xishuangbanna considerably impact the teaching order of the NCE. The monk students miss as many as 92 classes every semester to attend religious activities and folk festival activities (Dao, 2006). The monk students are keen to attend various activities so apply for absence to do so. The three teachers who participated in the interview also mentioned the negative influence of frequent religious activities on the teaching order of the NCE. T-1, for example, complained that, "there are so many festivals in the Dai community. When there is a festival, monk students will ask for leave to attend the religious event. They participate in activities very late in the night, affecting the rest of the night, and then they sleep in the classroom the next day".

\subsection{Conflict in Teaching Contents}

The main content taught in BTE is Buddhist sutras and the Dai language, which is markedly different from the NCE. One aspect of the conflicts is reflected in the contradiction between religion and science. The main function of BTE is to spread the Buddhist doctrine and creed, whereas the NCE is committed to the transmission of scientific and cultural knowledge. As noted by O'Toole, religion is the way of "rendering rational the irrationalities of life through the provision of meaning" (O'Toole, 1984: p. 142) and it is primarily concerned with "irrationalities, not science" (Evans \& Evans, 2008: p. 90). The long-standing academic hypothesis in the Chinese education circle holds that the religious system is incompatible with the scientific system (Seng, 2006) and the Regulations on Ethnic Education of Xishuangbanna Dai Autonomous Prefecture also deny the function of religion in school education. For example, article 35 of this Regulation argues that "religion should not interfere in the school education and the social public education, ... in schools, conducting religious practices is not permitted and superstitious activities should be prohibited" (The Law Publication Center of the PRC, 2002: p. 6).

Another conflict in teaching is embodied in the incompatibility between the "new" Dai language (Ch., xindaiwen) and the "old" Dai language (Ch., laodai- 
wen). The old alphabet or the classical Dai alphabet is used to write the Theravāda Buddhist scriptures, which is mainly taught and disseminated among monks through the BTE. The Chinese government enacted writing system reform of the old Dai alphabet in the 1950s and the new scripts have been promoted ever since. These two sets of alphabet are different (Borchert, 2008; Davis, 2003); as argued by T-2, "those who have learned the new script cannot recognize or understand the old script if they do not learn the old Dai language on purpose". Davis (2003) noted that the new script halted Dai's centuries-old written tradition (Davis, 2003). The new script is vigorously used in school education under the promotion of government, but its application is confined to governmental documents, which is almost useless in daily life. Consequently, as reported by MS-1, the students forget the new Dai language quickly after it is learned. However, the old Dai language is extensively applied in various festival activities and Buddhist ritual actions, which implies that the old script has more application value in Dai culture than the new script, though the old Dai language has not been supported by the government.

\section{Discussion}

The conflict between the BTE and the NCE is manifested in four dimensions: the legal sphere, students' academic achievement, admission age and schedule, and curriculum content. In this part, the possible causes of conflict are explained accordingly and the corresponding solutions are also discussed.

\subsection{Governmental Policies Gave Unprincipled Protection to the NCE}

The governments at all levels have formulated a series of policies to alleviate the contradictions between BTE and NCE, but almost all the policies favor NCE over BTE. For instance, article 35 of the Regulations on Ethnic Education of Xishuangbanna Dai Autonomous Prefecture state six obligations of BTE to guarantee the development of the NCE; however, BTE enjoys only one right, which is that "the school should not discriminate against the monk students" (The Law Publication Center of the PRC, 2002: p. 6). Chapter six of the Autonomous Regulations of Xishuangbanna Dai Autonomous Prefecture is composed of 12 articles, one-third of which are concerned about the development of the NCE, but this regulation says nothing about BTE.

The officials crudely employ binary thinking mode when addressing the conflict between the BTE and NCE. China's current laws set the stage for conflict between BTE and NCE, and the officials definitely emphasize the NCE over BTE. Therefore, BTE is forced to compromise when in conflict with NCE in terms of enrollment or curriculum arrangement. This can be reflected by the attitude of local cadres toward the BTE. LC-1 argued that "religion is a sensitive topic and it should be proscribed for it is contrary to the scientific spirit advo-

cated by school education". This represents the official view that BTE is part of 
religious activities and is incompatible with the NCE, which emphasizes scientism. The minister of Xishuangbanna's view has increased peoples' worry about the future of BTE. He proposed, "the Buddhist temples are not illegal, but one could say that they are illegal” (Davis, 2003: p. 196). Both the complementary effect and the co-flourishing of these two forms of education have not been seriously considered by Chinese governmental officials. The result must be, as Chen pointed out, that "not only will it not alleviate the conflict, but it will intensify the conflict" (Chen, 2011: p. 99).

Religions are not the great scourges of education. Instead, religions are important in people's lives (Iannaccone, 1998). Scientism has been rooted in China for more than one century, especially under the 70-year rule of communism, when the dominance of scientism on China's intellectual culture became more rigid (Yang, 2010). However, the dialogue between science and religion is indispensable, as religion helps people to reflect on science (Seng, 2006). Therefore, to promote the sustainable development of ethnic minority education in the Dai cultural region, the governmental policies need to throw aside the prejudice against religion that relgion was regarded as superstition and allow religion to play a positive role in education.

\subsection{Absence of Dai Culture and Neglect of Xishuangbanna's Realities Reduce Dai People's Enthusiasm for the NCE}

NCE in the Dai cultural region of Xishuangbanna neither educates about the Dai culture nor considers the Xishuangbanna's realities, which inevitably reduces Dai people's enthusiasm for NCE. This explains in part why the monk students' academic performance in school education is not satisfactory and how to mediate the conflict between these two forms of education in terms of teaching content.

First, as discussed in Section 4.4, the Dai culture is absent in NCE. For, as Meidl and Meidl (2013) pointed out, "the public schools are driven by specific lesson plans and skills with greater anchoring in state education departments' objectives" (Meidl \& Meidl, 2013: p. 179), which implies that it is impractical to require the public schools to shoulder the responsibility of diffusing the ethnic minority culture. As noted by Overmyer, most of the ethnic groups in the southwest of China "have maintained at least some of their own cultural, language, and religious traditions" (Overmyer, 2003: p. 312). In Xishuangbanna, the Dai culture interacts and blends deeply with Theravāda Buddhism, but the Chinese government assumes a negative attitude toward the religious elements in the education system, which further illustrates that the NCE would not be able to undertake the responsibility of transmitting the Dai culture.

The new Dai language is the only culture-related course in NCE of Xishuangbanna, but it is not compatible with the old Dai language. The school timetable of Menghan junior high school shows that the new Dai language is the only course that is related to Dai cultural inheritance. However, the palm-leaf Buddhist sutra, as the carrier of the Dai culture, was written in old Dai language, not 
the new Dai language that is taught in the NCE. It is understandable, then, why Davis (2003) would query whether the Chinese government's real incentive is "to increase literacy in Dai or to gradually eliminate it" (Davis, 2003: p. 191). T-1 also felt confused about this phenomenon:

The students are not highly motivated to learn the new Dai language; instead, they want to learn the old Dai language for they hardly use the new Dai language in daily life. The new Dai language is taught in school and its use is confined to the billboards and some governmental documents. Plainly speaking, the new Dai language's application range is narrow and it has little historic significance, so students' interests and efficiency in learning the new Dai language is not high. Contrarily, the old Dai language is frequently used in daily life, such as recording the donors' names or their wishes when they make donations to Buddhist temples. The Dai ancient classics, as well as the popular songs in the Dai cultural region, are all written in old Dai language.

Secondly, NCE neglects the actual situation in Xishuangbanna, which also dampens the local students' learning enthusiasm. Plenty of evidence suggests that the return from educational investment is the direct motive for individuals to accept education (Blundell et al., 1999; Escarbajal-Frutos et al., 2019). Education is regarded as a form of investment and the economic return is "an important outcome of education" (Guo et al., 2019: p. 2); however, NCE in Xishuangbanna does not have a directly positive effect on individuals' or families' in come (Chen, 2011). We agree with Blundell et al. that the income levels have little to do with individuals' qualifications if the economy lacks competitive vitality (Blundell et al., 1999). Xishuangbanna's economy is dominated by agriculture, which signifies that Dai people can live a relatively wealthy life despite only having primary diplomas. To the disappointment of Dai parents, they find that their children know nothing about agriculture, even after having spent nine years in public schools. Bates (1997) suggested that employment should be a quantitative index for assessing the efficiency of school outputs (Bates, 1997). However, the severe situation of China's present employment, that it is difficult for college students to find a relatively satisfactory job, may precipitate more parents and students to believe in the uselessness of study.

Based on the above discussion, we argue that Dai ethnic minority culture, such as Dai literature, Dai history, and old Dai language, is seriously lacking in NCE of Xishuangbanna. The agricultural economic model in Xishuangbanna and inadequate employment situation in China mean that the Dai people value agricultural knowledge rather than school education. BTE shoulders the responsibility of transmitting Dai culture and the teaching content, which includes Dai literature, old Dai language, and agricultural knowledge and technology, which means we should combine NCE with BTE to promote the sustainable development of ethnic minority education in Xishuangbanna.

\subsection{Economic Superiority Has Improved the Status of BTE}

The economic superiority of Xishuangbanna means that the Dai people attach 
more importance to BTE than NCE. Xishuangbanna is located in the southwest of the Yunnan province, China (Figure 1). Xishuangbanna has a tropical monsoon climate and the average annual temperatures here is 18 to 22 degrees Celsius (Thellmann et al., 2018). Xishuangbanna is plentiful in products and is also the home to one-quarter of China's animal species and one-sixth of the country's plant species, making it known as the animal kingdom and plant kingdom of China. The Dai people live in the most advantageous farms and the Dai ethnic minority has held long-term economic superiority. The local government introduced cash crops, such as rubber, tea, and sugarcane, in 2003, which increased the wealth of the Dai people (Sturgeon, 2012). In this region, Dai people can live a prosperous life using only primary farming methods that have been passed down from generation to generation. Compared with the developed eastern regions of China, however, the Dai people in Xishuangbanna are not in urgent need of the scientific and cultural knowledge that is imparted through NCE (Chen, 2011). The knowledge that is acquired from NCE cannot produce an immediate effect in increasing family income. Dai is the main nationality in Xishuangbanna, and the economic superiority makes Dai culture the mainstream culture in this region (Chen, 2011). Therefore, the Dai people attach more importance to BTE rather than NCE because both Dai culture and agricultural knowledge can be taught through the BTE instead of the NCE.

Comparatively, the Blangs mainly live in the mountainous area of Xishuangbanna. The Blangs are economically undeveloped because the arable land for this ethnic group is scarce and the transportation is inconvenient. Accordingly, the Blang culture has always been in a weak position. Therefore, compared with Dai ethnic minority, Blang parents are more apt to absorb the Han culture and send their children to receive the school education. SP-2 confirmed this opinion: "The Blangs attach great importance to their children's schooling. The main reason is that they live in mountainous areas and their life is lean; thus, they want to find a way out by attending school education".

\subsection{Religious Secularization and Lax Regulation Threaten the Sustainable Development of BTE}

Chinese students achieved better results than their counterparts from other cultural regions in international comparison studies (Hu et al., 2018; Leung, 2002; Organization for Economic Co-operation and Development, 2016), but the monk students in the Dai cultural region are criticized as bad learners due to their poor scholastic performance (Shen \& Qian, 2010). The reasons for the decline of BTE's teaching quality can be explored from the perspective of the religious secularization of Theravāda Buddhism in Xishuangbanna and the Buddha's lax regulation of monk students.

In the context of commercialism in modern China, the sacredness of Buddhism is being gradually eroded (Long, 2002). One adverse impact of the contemporary commercial economy on religious life in Xishuangbanna is that the Buddhist activities have become secular (Gong, 2003; Qu, 1999) The daily activi- 
ties of the Buddha also reflect the secularization of Theravāda Buddhism in Xishuangbanna. One Buddha in Menghai County (B-1) told us, "Villagers ordinarily invite us to recite sutras at weddings or funerals. Someone who has mild disease will also ask us to recite sutras for them instead of going to the hospital. But they will go to the hospital if they are seriously ill".

The Dai people's belief in Theravāda Buddhism has become secular, which is bound to alter their attitudes toward BTE. The Buddha's daily activity, in the above case, reflects that Dai people no longer believe in the Buddhist patriarch wholeheartedly. Buddhist activities, such as sutra recitation, have only a ritual significance and Dai people choose to trust modern medicine, but not the Buddhist patriarch, when they are severely ill. Dai people's religious sentiments are more for rational reasons than pure faith; that is, they consider more about whether the religious activities can benefit them. Therefore, the first thing Dai parents think about when sending their children to Buddhist temples is whether BTE can increase their income and wealth (Chen, 2011; Chen \& Liu, 2011).

There are three reasons for the lax regulation of the BTE, which has further diluted the BTE's teaching quality. First, the monks' status in the Dai cultural region has changed from the disciples of the Buddhist patriarch to ordinary children. In tradition, only the Buddha has the right to rule over the monks, but now the Buddha seldom scold them; otherwise, the monks' parents complain. Secondly, the Buddha's tendency of being young is not conducive to the management of the monk students. After visiting the Buddhist temples in Xishuangbanna, we found that most of the Buddha are in their 20s. As Yan (2006) stated, "Among the 4500 monks in Xishuangbanna, only 50 or so Buddha are over 30" (Yan, 2006: p. 60). These young Buddha have low self-expectations and they seldom supervise the monks. Thirdly, the Buddha's teaching ability also challenges the survival of BTE. Fewer than half of the Buddha in Xishuangbanna have received formal Buddhist education (Yan, 2006), but many studies have shown that the teaching quality has a decisive effect on students' grades and performance (Card \& Krueger, 1992, 1998; De Paola, 2009) thus, the Dai parents find it hard to trust BTE if Buddha's cultural attainments are low.

\section{Conclusion and Implication}

The conflicts between BTE and NCE and the possible reasons that lead to these conflicts were explored through field investigation in this study. We found that the conflicts between these two forms of education are mainly reflected in four aspects: the legal sphere, students' academic performance, the admission age and schedule, and the teaching content. The possible reasons that lead to these conflicts were also discussed. We proposed that the economic superiority has won the Dai culture a prominent position in Xishuangbanna and the conflicts between these two forms of education are inevitable because China's governmental policies neglect the Dai culture and the realities of Xishuangbanna, but provide unprincipled protection to the NCE. The deficiencies of the NCE and the BTE 
were also discussed. We argue that neither NCE nor BTE can be responsible on their own for the development of ethnic minority education in the Dai cultural region of Xishuangbanna. Therefore, the key to the sustainable development of the ethnic minority education in this region lies in the coordination and cooperation between NCE and BTE. In other words, an appropriate balance and deep integration of these two forms of education that consider both the Dai cultural inheritance and the contemporary scientific knowledge is the only way to realize the sustainable development of ethnic minority education in Xishuangbanna.

Given the context in which China aims to establish Han culture as dominant throughout China through NCE, both of these two forms of education need to appropriately adjust their goals and approaches in Xishuangbanna. For, as argued by Vesely-Flad (2017), religious sentiment and practice rather than the economic prosperity are the foundations of social harmony (Putnam \& David, 2010; Vesely-Flad, 2017) and especially to those less-developed countries or regions that once under the rule of the Soviet Union the economic integration in a nation-state could threaten local identities (Juergensmeyer, 2019). Besides, education cannot be separated from culture (Brand et al., 2006); thus, it is vital for the Chinese government to attach importance to the significance of Dai culture and incorporate Dai culture into the school curriculum. Simultaneously, the educational institution has the responsibility to counter localism (Escarbajal-Frutos et al., 2019), which means that the stakeholders need to change their conventional conception that regards BTE as an obstacle to NCE. The knowledge that the Dai people need but cannot spread through the NCE, such as Dai literature and religious beliefs, can be learned and transmitted through BTE. In short, only the co-flourishing of BTE and NCE can lead to the sustainable development of ethnic minority education in the Dai cultural region of Xishuangbanna.

The study has several drawbacks in terms of methods. Firstly, interviewing approach and documentary review were used in this study to explore the relationship between BTE and NCE. For the future work in this field, we recommend to conduct quantitative research through questionnaire survey to grasp the relationship between these two forms of education more comprehensively and accurately. Secondly, the conflicts between BTE and NCE and the possible causes that lead to conflicts were explored in the study, however, the exclusion and fusion of Dai culture and Han culture has not been discussed. To find the sustainable development path of ethnic minority education in Xishuangbanna, more studies consider the interactive relationship between regional ethnic culture and national mainstream culture is needed. Thirdly, as described in Section 2.2, China's religious policy could determine the interrelationship between BTE and NCE but the development dimension of which was not explored in the study. It is suggested to carry out diachronic study to investigate the development process of China's religious policy and its effect on the relationship between BTE and NCE. 


\section{Conflicts of Interest}

The authors declare no conflicts of interest regarding the publication of this paper.

\section{References}

Bates, J. M. (1997). Measuring Predetermined Socioeconomic "Inputs" When Assessing the Efficiency of Educational Outputs. Applied Economics, 29, 85-93. https://doi.org/10.1080/000368497327434

Blundell, R., Dearden, L., Meghir, C., \& Sianesi, B. (1999). Human Capital Investment: The Returns from Education and Training to the Individual, the Firm and the Economy. Fiscal Studies, 20, 1-23. https://doi.org/10.1111/j.1475-5890.1999.tb00001.x

Borchert, T. (2008). Worry for the Dai Nation: Sipsongpanna, Chinese Modernity, and the Problems of Buddhist Modernism. The Journal of Asian Studies, 67, 107-142. https://doi.org/10.1017/S0021911808000041

Brand, B. R., Glasson, G. E., \& Green, A. M. (2006). Sociocultural Factors Influencing Students' Learning in Science and Mathematics: An Analysis of the Perspectives of African American Students. School Science and Mathematics, 106, 228-236. https://doi.org/10.1111/j.1949-8594.2006.tb18081.x

Brown, S. W. (2002). Hispanic Students Majoring in Science or Engineering: What Happened in Their Educational Journeys? Journal of Women and Minorities in Science and Engineering, 8, 123-148. https://doi.org/10.1615/JWomenMinorScienEng.v8.i2.20

Card, D., \& Krueger, A. B. (1992). Does School Quality Matter? Returns to Education and the Characteristics of Public Schools in the United States. The Journal of Political Economy, 100, 1-40. https://doi.org/10.1086/261805

Card, D., \& Krueger, A. B. (1998). School Resources and Student Outcomes. The Annals of the American Academy of Political and Social Science, 559, 39-53. https://doi.org/10.1177/0002716298559001004

Chang, K. (2018). New Wine in Old Bottles: Sinicisation and State Regulation of Religion in China. China Perspectives, 1-2, 37-44.

https://doi.org/10.4000/chinaperspectives.7636

Chen, H. (2011). The Status Quo of the Conflict between the Monastic Education and School Education of the Dai in Xishuangbanna and Its Attribution Analysis. Journal of Education Studies, 7, 89-100.

Chen, X., \& Liu, H. (2011). The Current Plight and Protection of Dai Temple Education. Journal of Honghe University, 9, 107-110.

Dao, C., \& Cai, R. (2014). The Cultural History of the Dai (2nd ed.). Kunming: Yunnan Ethnic Publishing House.

Dao, R. (2006). Research Report on the Development Strategy of Dai Ethnic Minority Education in Xishuangbanna. Kunming: Yunnan Arts Press.

Davis, S. (2003). Premodern Flows in Postmodern China: Globalization and the Sipsongpanna Tais. Modern China, 29, 176-203. https://doi.org/10.1177/0097700402250738

De Paola, M. (2009). Does Teacher Quality Affect Student Performance? Evidence from an Italian University. Bulletin of Economic Research, 61, 353-377. https://doi.org/10.1111/j.1467-8586.2008.00299.x

Escarbajal-Frutos, A., Izquierdo-rus, T., Aznar-diaz, I., \& Caceres-Reche, M. P. (2019). Intercultural and Community Schools. Learning to Live Together. Sustainability, 11, 3734. https://doi.org/10.3390/su11133734 
Evans, J. H., \& Evans, M. S. (2008). Religion and Science: Beyond the Epistemological Conflict Narrative. Annual Review of Sociology, 34, 87-105. https://doi.org/10.1146/annurev.soc.34.040507.134702

Gong, R. (2003). Seculariation of Religious Life in Xishuangbanna: Taking the Three Towns of Gasha, Menghan, and Damenglong as Examples. Ethno-National Studies, 2, 36-43.

Guo, L., Huang, J., \& Zhang, Y. (2019). Education Development in China: Education Return, Quality, and Equity. Sustainability, 11, 3750. https://doi.org/10.3390/su11133750

Hansen, M. H. (1999). Lessons in Being Chinese: Minority Education and Ethnic Identity in Southwest China. Hong Kong: Hong Kong University Press.

Heberer, T. (2017). China and Its National Minorities: Autonomy or Assimilation: Autonomy or Assimilation. Abingdon-on-Thames: Routledge.

Hu, X., Leung, F. K. S., \& Teng, Y. (2018). The Influence of Culture on Students' Mathematics Achievement across 51 Countries. International Journal of Science and Mathematics Education, 16, 7-24. https://doi.org/10.1007/s10763-018-9899-6

Iannaccone, L. R. (1998). Introduction to the Economics of Religion. Journal of Economic Literature, XXXVI, 1465-1496.

Jeynes, W. H. (1999). The Effects of Religious Commitment of the Academic Achievement of Black and Hispanic Children. Urban Education, 34, 458-479.

https://doi.org/10.1177/0042085999344003

Jeynes, W. H. (2003). The Effects of Religious Commitment on the Academic Achievement of Urban and Other Children. Education and Urban Society, 36, 44-62. https://doi.org/10.1177/0013124503257206

Juergensmeyer, M. (2019). Religious Nationalism in a Global World. Religions, 10, 97. https://doi.org/10.3390/rel10020097

Lemke, J. L. (2001). Articulating Communities: Sociocultural Perspectives on Science Education. Journal of Research in Science Teaching, 38, 296-316. https://doi.org/10.1002/1098-2736(200103)38:3<296::AID-TEA1007>3.0.CO;2-R

Leung, F. K. S. (2002). Behind the High Achievement of East Asian Students. Educational Research and Evaluation, 8, 87-108. https://doi.org/10.1076/edre.8.1.87.6920

Li, J., \& Moore, D. (2014). Reconsideration of the Coexistence of Buddhist Temple Education and State Education in Xishuangbanna, China. British Journal of Religious Education, 36, 139-154. https://doi.org/10.1080/01416200.2013.783791

Liao, X. (2019). China: Some Exceptions of Secularization Thesis. Religions, 10, 56. https://doi.org/10.3390/rel10010056

Long, D. (2002). Buddhist Education in Sichuan. Educational Philosophy and Theory, 34, 185-206. https://doi.org/10.1111/j.1469-5812.2002.tb00297.x

Macpherson, S. (2006). The Adulthood of Buddhahood: Buddhism, Lifelong Learning and the Education of Desire. International Journal of Lifelong Education, 15, 455-470. https://doi.org/10.1080/0260137960150605

Meidl, C., \& Meidl, T. (2013). Character Education in Three Schools: Catholic, Quaker and Public. Education 3-13, 41, 178-187. https://doi.org/10.1080/03004279.2011.566885

Nanbu, H. (2008). Religion in Chinese Education: From Denial to Cooperation. British Journal of Religious Education, 30, 223-234. https://doi.org/10.1080/01416200802170151

National People's Congress (2018). Constitution of the People's Republic of China. Beijing: China Legal Publishing House. 
National People's Congress of China (2016). The Education Law of the People's Republic of China. Beijing: China Legal Publishing House.

O’Toole, R. (1984). Religion: Classic Sociological Approaches. Toronto: McGraw-Hill Ryerson.

Organization for Economic Co-operation and Development (2016). PISA 2015 Results (Volume I):Excellence and Equity in Education. Paris: OECD Publications.

Overmyer, D. L. (2003). Religion in China Today: Introduction. The China Quarterly, 174, 307-316. https://doi.org/10.1017/S0009443903000196

Patton, M. Q. (2001). Qualitative Research and Evaluation Methods. In Qualitative Inquiry (3rd ed.). Thousand Oaks, CA: Sage.

Presmeg, N. C. (1998). Ethnomathematics in Teacher Education. Journal of Mathematics Teacher Education, 1, 317-339. https://doi.org/10.1023/A:1009946219294

Putnam, R., \& David, E. C. (2010). American Grace: How Religion Divides and Unites Us. New York: Simon and Schuster.

Qu, M. (1999). The Fluctuating Region: On the Secularization of Religious Life in Xishuangbanna. Studies in World Religions, 1, 123-130.

Seng, K. P. (2006). Bridging Science and Religion in China: Emerging Opportunities for Global Dialogue. Theology and Science, 4, 183-192.

https://doi.org/10.1080/14746700600759018

Shen, H., \& Qian, M. (2010). The Other in Education: The Distance between School Education and Local Culture. Chinese Education and Society, 43, 47-61. https://doi.org/10.2753/CED1061-1932430503

Sturgeon, J. C. (2012). The Cultural Politics of Ethnic Identity in Xishuangbanna, China: Tea and Rubber as "Cash Crops" and "Commodities". Journal of Current Chinese Affairs, 41, 109-131. https://doi.org/10.1177/186810261204100404

The Law Publication Center of the PRC (Ed.) (2002). Regulations on Ethnic Education of Xishuangbanna Dai Autonomous Prefecture. Beijing: Law Press.

The NPC Standing Committee (2001). Law of the People's Republic of China on Regional, National Autonomy. Beijing: The Ethnic Publishing House.

The NPC Standing Committee (2015). The Compulsory Education Law of the People's Republic of China. Beijing: China Legal Publishing House.

Thellmann, K., Cotter, M., Baumgartner, S., Treydte, A., \& Cadisch, G. (2018). Tipping Points in the Supply of Ecosystem Services of a Mountainous Watershed in Southeast Asia. Sustainability, 10, 2418. https://doi.org/10.3390/su10072418

Vermander, B. (2019). Sinicizing Religions, Sinicizing Religious Studies. Religions, 10, 137. https://doi.org/10.3390/rel10020137

Vesely-Flad, R. (2017). Black Buddhists and the Body: New Approaches to Socially Engaged Buddhism. Religions, 8, 239. https://doi.org/10.3390/rel8110239

Voas, D. (2014). Does Education Develop or Diminish Spirituality in Taiwan? Journal for the Scientific Study of Religion, 53, 556-574. https://doi.org/10.1111/jssr.12128

Wang, X., \& Uecker, J. E. (2017). Education, Religious Commitment, and Religious Tolerance in Contemporary China. Review of Religious Research, 59, 157-182. https://doi.org/10.1007/s13644-017-0286-5

Yan, X. (2006). From the Worship of Buddhism to the Buddhist Temple Education. China Religion, 3, 60-61.

Yang, F. (2004). Between Secularist Ideology and Desecularizing Reality: The Birth and Growth of Religious Research in Communist China. Sociology of Religion, 65, 101-119. 
https://doi.org/10.2307/3712401

Yang, F. (2010). Religion in China under Communism: A Shortage Economy Explanation. Journal of Church and State, 52, 3-33. https://doi.org/10.1093/jcs/csp042

Zern, D. S. (1989). Some Connections between Increasing Religiousness and Academic Accomplishment in a College Population. Adolescence, 24, 141-154.

Zheng, Y. (2011). On the Conflict and Its Solution between Dai's Buddhist Temple Training and National Compulsory Education. Guizhou Ethnic Studies, 32, 142-147.

Zheng, Y. (2012). Conflict and Harmony: Research on the Relationship of Basic Rights between Buddhist Temple Education and National Contemporary Education. Beijing: Minzu University of China.

Zheng, Y., \& Xiong, W. (2013). Special Modes of Conflict of Rights and Solutions: The Conflict between Buddhist Temple Education and Compulsory Education in Xishuangbanna. Journal of Research on Education for Ethnic Minorities, 24, 21-27. 